\title{
Serum Magnesium Levels in Acute Myocardial Infarction
}

\author{
Dr. A. Akila, M.D ${ }^{1}$,Dr. J.Anandaraj M.D ${ }^{2}$ Dr. Srinivasan Karthikeyan ${ }^{3}$ \\ ${ }^{1}$ Assistant Professor, Coimbatore Medical College Hospital, Coimbatore \\ ${ }^{2}$ Assistant Professor, Government Medical College, Omandurar Government Estate, Chennai. \\ ${ }^{3}$ Junior Resident, Coimbatore Medical College Hospital, Coimbatore
}

\begin{abstract}
Introduction: Magnesium has been implicated in the pathogenesis of acute myocardial infarction and its complication like arrhythmia. Magnesium improves myocardial metabolism, inhibits calcium accumulation and myocardial cell death. It improves vascular tone, peripheral vascular resistance, after load and cardiac output, reduces cardiac arrhythmias and improves lipid metabolism. Magnesium also reduces vulnerability to oxygen derived free radicals, improves endothelial function and inhibits platelet function including platelet aggregation and adhesion.

Objective: To know the relationship between the serum magnesium levels and arrhythmias in patients with acute myocardial infarction.

Method: By using simple random method, 50 cases of acute myocardial infarction, admitted in Coimbatore Medical College and Hospital over a period of one year.

Results: There is a significant difference in the magnesium levels in patients with arrhythmias and without arrhythmias.

Conclusion: In acute myocardial infarction, patients with low magnesium levels are more prone to get arrhythmias. So magnesium treatment can be considered in patients of acute myocardial infarction with low magnesium levels.
\end{abstract}

\section{Introduction}

Magnesium has been known to have an influence in the causation of acute myocardial infarction and also its sequelae like arrhythmias. It plays a major role in the pathogenesis of other cardiovascular diseases as well. Magnesium ions are found to be essential for the maintenance of the normal functional integrity of the myocardium ${ }^{1}$.Several investigations have shown that the serum magnesium level is low in the first 48 hours following a acute myocardial infarction and later on rose gradually to attain the normal level in about three weeks time. Infarcted myocardium was found to have reduced magnesium concentration. The above said findings correlated directly with the associated complications of acute myocardial infarction, such as arrhythmias.In patients with sudden death because of ischemic heart disease, magnesium concentration in the cardiac muscle was found to be decreased ${ }^{2}$. Hypo-magnesium acts a provoking factor in the occurrence of ventricular fibrillation, which is usually the cause of sudden death in IHD. The coronary vasospasm which occurs as a result of hypomagnesemia has been considered as an important factor in the causation of sudden death in IHD.Magnesium deficiency contributes to the progression of atheromatous plaques occurring as a result of hyperlipidemia. Myocardial infarction is one of the common causes of death where its prognosis depends on various factors. This study is designed to know the contribution of magnesium levels in the serum of acute MI patients to the occurrence of arrhythmias.

\section{Aims and objectives}

To know the correlation between serum magnesium levels and arrhythmias in patients with acute myocardial infarction who are presenting within 12 hours of onset of symptoms.

\section{Materials And Methods}

The study was conducted after ethical clearance from ethics committee at Coimbatore medical collegeand hospital, Coimbatore. Biochemical analysis was done in department of biochemistry, Coimbatore. Informedconsent in the prescribed form was obtained from all patients included in the study after explanation of theprobable benefits in local language. About 50 patients diagnosed of having acute myocardial infarction, admitted to IMCU, Coimbatore medical college and hospital, over a period of 1 year were selected by using simple random method.

\section{Selection of patients:}

Inclusion Criteria:

Patients who presented to the hospital within 12 hours of onset of symptoms were included in the study. 
The following criteria has been used to diagnose acute myocardial infarction. The presence of any of the two criteria has been considered :

1. History of discomfort in the chest.

2. Changes in the ECG suggestive of acute myocardialinfarction

3. Rise of cardiac enzymes.

\section{Exclusion Criteria:}

1. Patients having hypokalemia.

2. Patients on diuretics

After the selection of patients through random method, after obtaining informed written consent from all the patients included in the study, relevant history and physical examination was done. Patients were subjected to undergo investigations like complete blood count, urine examination, blood sugar, blood urea, serum creatinine, fasting lipid profile, cardiac enzymes and ECG was done in all cases.

Estimation of serum magnesium level was done on day 1 and day 5.

\section{Method of estimation serum magnesium:}

The method used was colorimetric end point test with Xylidyl blue as the reagent. Magnesium standard: $2.5 \mathrm{mg} / \mathrm{dL}$.

\section{Principle:}

Magnesium reacts with xylidyl blue at alkaline $\mathrm{pH}$ resulting in the formation of a chelating red colored compound. The increase in the red colour (or) the decrease in blue color are proportionate to the concentration of magnesium in the serum..

\section{Specimen:}

Analysis of non-hemolyzed serum or lithium heparin plasma may be done since the concentration of magnesium inside the red cells is 10 times greater than that in the ECF. Separation of serum from the cell should be done as early as possible and hemolysis should be avoided.

\section{Normal range for magnesium}

Serum magnesium: $1.6-2.4 \mathrm{mg} / \mathrm{dl}$.

\section{Results}

In this study group of 50 cases, 42 were males and 8 were female patients with a male-female ratio of 5.25:1. The maximum Incidence of acute myocardial infarction was seen in the 4th and 5th decades, followed by 6 th and 7 th decades. $28 \%$ patients were in the age group of 4 th and 5 th decade, $22 \%$ were in the age group of 60-70.

Diet:

In the study of 50 patients, $15(30 \%)$ patients were vegetarian by diet and $35(70 \%)$ of them consumed mixed diet. Non-vegetarian run higher risk of acute myocardial infarction owning to their higher content of cholesterol in their diet compared to the vegetarian.

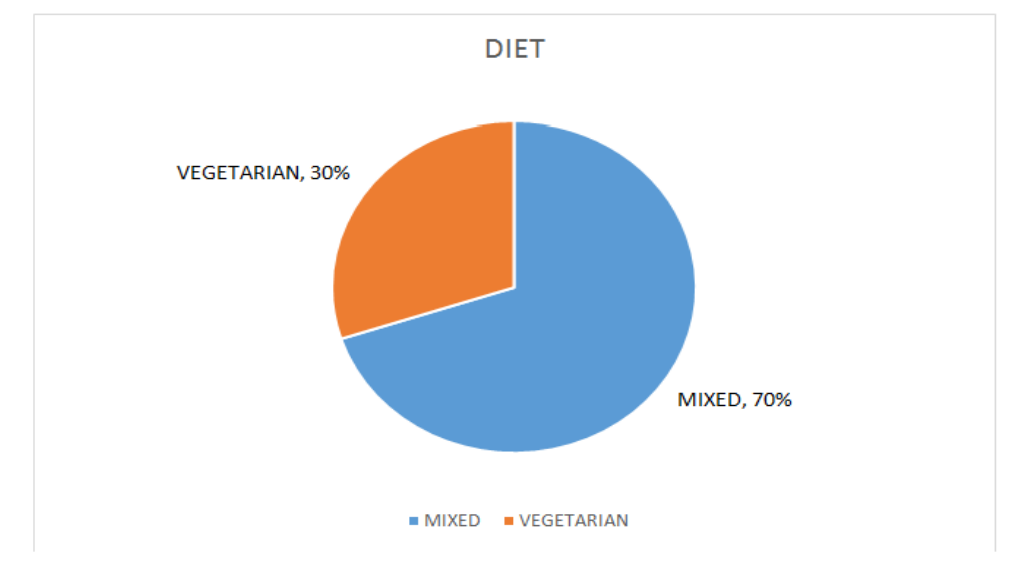




\section{Smoking}

In the study, smoking is the most common risk factor found in the patients with acute myocardial infarction. Cigarette smoking accelerates coronary atherosclerosis in both sexes and at all ages and increases the risk of thrombosis, plaque instability and myocardial infarction. In addition, by increasing myocardial oxygen needs and reducing oxygen supply, it aggravates angina.

\section{Obesity}

In the present study, out of 50 patients, $12(24 \%)$ were found to be obese based on National Cholesterol Education Programme. Waist circumference was measured in all patients. Men whose waist circumference is more than $102 \mathrm{~cm}$ and females whose waist circumference is more than $88 \mathrm{cms}$ were considered to be obese. In the present study of 50 patients, 15 (30\%) patients were found to be hypertensive. Patients whose blood pressure is more than $130 / 85$ are considered to be hypertensive.

In the present study of 50 patients, $18(36 \%)$ patients were found to be diabetics and $12(24 \%)$ patients were found to be dyslipidemic.

\begin{tabular}{|l|l|l|}
\hline Risk factors & No. of cases & Percentage \\
\hline & & \\
\hline Smoking & 35 & 70.00 \\
\hline & & \\
\hline Family history of HTN, DM, IHD, & 10 & 20.00 \\
\hline CVA & & \\
\hline & & 24.00 \\
\hline Obesity & 12 & \\
\hline & & 30.00 \\
\hline Hypertension & 15 & \\
\hline & & 36.00 \\
\hline Diabetes mellitus & 18 & \\
\hline & & 12.00 \\
\hline Dyslipidemia & 6 & \\
\hline & &
\end{tabular}

In the present study, 23 (46\%) cases presented to the hospital between 3-6 hours of onset of symptoms and $14(28 \%)$ cases presented between $0-3$ hours.

\section{Presentation to the Hospital}

Chest pain was the commonest symptom and was present in all of the patients in the present study $(100 \%)$. In this study chest pain is associated with sweating $13(26 \%)$ of patients. Chest pain is associated with breathlessness in $8(16 \%)$ of the patients. Palpitation associated with chest pain was present in 1 patient $(2 \%)$.

\section{Variation in type of Myocardial Infarction}

In the present study of 50 patients, $21(42 \%)$ patients had anterior wall MI, $17(34 \%)$ patients had inferior wall MI and $9(18 \%)$ patients had anteroseptal MI and $3(6 \%)$ patients had anterolateral MI

Serum magnesium level in acute myocardial infarction in relation to arrhythmia In this cross sectional study of 50 patients, the mean serum magnesium level on day-1 in all 50 patients was $1.86 \pm 0.39$ and the mean serum magnesium level on day-5 was $2.26 \pm 0.5$. Mean serum magnesium level in the group with Arrhythmia on Day-1and Day-5

In the present study, out of 50 patients 25 patients had significant ventricular premature contractions or ventricular tachycardia or ventricular fibrillation during their 5 -days course in the hospital.

Serum magnesium levels in patients with arrhythmias

\begin{tabular}{|l|l|l|l|l|}
\hline Serum magnesium & Day-1 & Percent & Day-5 & Percent \\
\cline { 1 - 4 } levels $(\mathrm{mg} / \mathrm{dL})$ & & & & \\
\hline$<1.6$ & 8 & 16.00 & 2 & 4.00 \\
\hline 1.6 to 2.40 & 17 & 34.00 & 16 & 32.00 \\
\hline$>2.4$ & -- & -- & 2 & 4.00 \\
\hline
\end{tabular}

Serum magnesium levels in patients without arrhythmias

\begin{tabular}{|l|l|l|l|l|}
\hline Serum magnesium & Day-1 & Percent & Day-5 & Percent \\
\cline { 1 - 2 } levels (mg/dL) & & & & \\
\hline$<1.6$ & 2 & 4.00 & -- & -- \\
\hline 1.6 to 2.40 & 17 & 34.00 & 14 & 28.00 \\
\hline$>2.4$ & 6 & 12.00 & 9 & 18.00 \\
\hline
\end{tabular}




\begin{tabular}{|l|l|l|}
\multicolumn{4}{|c|}{ Mean serum magnesium level } \\
\hline $\begin{array}{l}\text { Mean serum magnesium level in } 50 \\
\text { cases }\end{array}$ & $1.86 \pm 0.39$ & $2.26 \pm 0.50$ \\
\hline $\begin{array}{l}\text { Mean serum magnesium level in patients } \\
\text { with arrhythmia(25patients) }\end{array}$ & $1.65 \pm 0.26$ & $1.98 \pm 0.25$ \\
\hline
\end{tabular}

\section{Comparison of Serum Magnesium level in patients with Arrhythimas and without Arrhythmias (Day-1)}

\begin{tabular}{|l|l|l|l|l|}
\hline & No. of Cases & $\begin{array}{l}\text { Serum magnesium } \\
\text { Day-1 }\end{array}$ & $\begin{array}{l}\text { t- } \\
\text { value }\end{array}$ & p-value \\
\hline $\begin{array}{l}\text { Mean serum magnesium } \\
\text { level in patients with } \\
\text { arrhythmia }\end{array}$ & 25 & $1.65 \pm 0.26$ & & \\
\hline & & & & \\
\hline $\begin{array}{l}\text { Mean serum magnesium } \\
\text { level in patients without } \\
\text { arrhythmia }\end{array}$ & 25 & $2.08 \pm 0.41$ & 4.63 & $<0.001$ \\
\end{tabular}

The above table shows that out of 50 patients, 25 patients had arrhythmias. The mean value of serum magnesium on day-1 those with arrhythmias is $1.65 \pm 0.26$ those without arrhythmias is $2.05 \pm 0.4(p<0.001)$. There is a significant difference in the magnesium level in patient with arrhythmias and without arrhythmias.

\section{Comparison of Serum Magnesium level in patients with Arrhythimas and without Arrhythmias (Day-5)}

\begin{tabular}{|l|l|l|l|l|}
\hline & No. of cases & $\begin{array}{l}\text { Serum } \\
\text { Magnesium Day-5 }\end{array}$ & t- value & p-value \\
\hline $\begin{array}{l}\text { Mean serum magnesium } \\
\text { level in patients with } \\
\text { Arrhythmia }\end{array}$ & 20 & $1.98 \pm 0.25$ & 4.17 & $<0.001$ \\
\hline $\begin{array}{l}\text { Mean serum magnesium } \\
\text { level in patients without } \\
\text { Arrhythmia }\end{array}$ & 23 & $2.48 \pm 0.52$ & & \\
\hline
\end{tabular}

The above table shows that serum magnesium level in patients with arrhythmia on Day- 5 is $1.98 \pm 0.25$ and in those without arrhythmia is $2.48 \pm 0.5$. The difference between these two is found to be statistically significant with $\mathrm{p}$ - value $(\mathrm{p}<0.001)$.

Mortality:

In the above study of 50 patients, 7 patients died during their 5 days hospital course. 5 patients were died of ventricular tachycardia or ventricular fibrillation, 2 patients were died of cardiogenic shock. Mortality percentage was $14 \%$

\section{Discussion}

Magnesium ion has recently been considered as a principle cardiovascular cation. It has many critically significant roles in the maintenance of normal homeostasis of the body. It plays a major role in cardiac homeostasis. Magnesium is essential ATP activation necessary for the maintenance of the sodium-potassium pump. Magnesium deficiency has been attributed to the causation of arrhythmias in acute myocardial infarction patients.

In the study group comprising of 50 patients, 42 were males and 8 were females with a male-female ratio of 5.25:1. The maximum incidence of acute myocardial infarction was seen in the 4 th and 5 th decades. In the present study of 50 patients, the mean serum magnesium level on day- 1 in all 50 patiens was $1.86 \pm 0.39$ and the mean serum magnesium level on day-5 was $2.26 \pm 0.5$.

Abraham et al studied the level of serum magnesium in 65 patients admitted and diagnosed to have acute myocardial infarction. Concentration of magnesium in serum was noticed to be reduced in patients who were diagnosed with AMI (mean $1.70 \mathrm{mg} / \mathrm{dl}$, p<0.001) or acute coronary insufficiency (mean $1.61 \mathrm{mg} / \mathrm{dl}$, $\mathrm{p}<0.01$ ), but was not seen in the control group or patients had chest pain of non cardiac origin (mean 1.91 $\mathrm{mg} / \mathrm{dl}$ ). Singh A et al investigated magnesium levels in the serum of twenty patients diagnosed of having acute myocardial infarction on the 1st, 7th and 12th day of admission. In most of the cases, there was a marked reduction in the magnesium level of the serum on the first day. Dimtruk conducted the study among 67 patients diagnosed with ischemic heart disease and made out that there was a remarkable decrease in the magnesium levels in the serum during the first 3 days from the time of presentation and found that the magnesium levels returned back to normal by 15-25 days from the time of presentation.

Sachdev et al (1978) selected 30 patients, diagnosed with myocardial infarction and monitored the magnesium levels within 24 hours, 5th and 8th day and it was found to be $1.83 \pm 0.087 \mathrm{mgm} \%, 1.91 \pm 0.149$ and 
$1.97 \pm 0.089$ whereas in the control group, it was $2.44 \pm 0.162 \mathrm{mgm} \%$. The values were reported to be statistically reduced on all the three days and increased thereafter. In the present study, the serum magnesium level on day-1 was significant lower in patients with arrhythmias than those without arrhythmia $(\mathrm{p}<0.001)$. There was an increase in serum magnesium from Day- 1 to Day-5 in both those with arrhythmias and those without arrhythmias. Ceremuzynski et al selected 48 patients with acute myocardial infarction of duration over 24 hours and infused magnesium or placebo. The occurance of ventricular tachycardia ( 3 or more subsequent premature ventricular beats with a rate more than $120 / \mathrm{min})$ was significantly decreased $(\mathrm{p}<0.001)$, but the occurance of other ventricular arrhythmias was unaffected.

Raismusen et al selected 273 patients with diagnosis of acute myocardial infarction and subjected them to IV administration of magnesium or placebo. A significant reduction in the occurance of ventricular arrhythmia in the magnesium group was noticed when compared to placebo group $(\mathrm{p}<0.05)$.

Shecter et al subjected 103 patients diagnosed of having acute myocardial infarction to magnesium infusion or placebo for 48 hours. A significant fall in mortality rate $(\mathrm{p}<0.01)$ was found. The occurance of tachyarrhythmias in need of treatment (10/50) has been very low in the magnesium group when compared to the placebo group (24/53). Smith et al randomly administered 24 hours continuous magnesium sulphate infusion or placebo in 400 patients with the suspicion AMI. Out of which, 200 patients were diagnosed of having acute myocardial infarction. There is no significant variation in the mortality rate or the occurance of ventricular dysrhythmia in need of treatment among the magnesium and placebo groups. Abraham et al randomly allocated 94 patients diagnosed of having acute myocardial infarction and administered a daily bolus of magnesium of about 30 mmol or placebo for 3-days. No significant variation was noticed in the mortality rate or life threatening arrhythmias among patients on magnesium treatment and with placebo.

Felstedt et al randomly subjected 298 patients with the suspicion of acute myocardial infarction to magnesium infusion or placebo for 24 hours. Myocardial infarction was confirmed in 162 patients. During 245 days period, no variation was noted in the occurance of tachyarrhythmias. Increase in the occurance of bradyarrhythmias was noted among patients infused with magnesium. Singh et al subjected 264 patients with suspicion of acute myocardial infarction to potassium, magnesium, $2 \%$ glucose or $10 \%$ glucose infusion. 228 patients were confirmed to have myocardial infarction. There was no difference in the mortality rate and ventricular tachycardia or fibrillation between the two groups.

Morton et al assigned 76 patients to get either magnesium infusion $0.38 \mathrm{mmol} / \mathrm{l}$ per $\mathrm{kg}$ every 12 th hourly or placebo for the first 36 hours of hospital stay. No difference was noticed in the occurance of ventricular tachycardia among the two study groups. Dyckner T et al, among 905 admission, found 342 patients with acute myocardial infarction, 563 with other diagnoses. Both acute myocardial infarction and non AMI group had markedly reduced serum magnesium levels compared to the reference group. The occurance of life threatening ventricular premature beats, ventricular tachycardia or ventricular fibrillation on admission was found to be high in patients with acute myocardial infarction with reduced serum magnesium levels.

\section{Summary}

This study was carried out in 50 patients of acute myocardial infarction who are admitted to the ICCU, Coimbatore Medical College Hospital, Coimbatore.

1. The male to female ratio in the study group was 5.25:1 and the maximum incidence of acute myocardial infarction was seen in 4th and 5th decade.

2. In the study Hindus were $78 \%$ and Muslim were $22 \%$.

3. In the study, the most common presentation symptom was chest pain and is associated with sweat in $26 \%$ of patients and breathlessness in $16 \%$ of patients and palpitation in $2 \%$.

4. In the study, the most common risk factor found was smoking followed by hypertension and diabetes.

5. In the study group, mean serum magnesium level in 50 patients on day- 1 is $1.86 \pm 0.39$ and on day-5 is $2.26 \pm 0.5$.

6. In the study group, mean serum magnesium level in 25 patients with arrhythmia is $1.65 \pm 0.26$ on day- 1 and $1.98 \pm 0.25$ on day -5 .

7. In the study group, mean serum magnesium level in 25 patients without arrhythmia is $2.05 \pm 0.41$ on day-1 and $2.48 \pm 0.52$ on day- 5 .

8. The difference between the magnesium level in patients with arrhythmia and without arrhythmia is statically significant on both day- 1 and day- 5 .

\section{References}

[1]. Burch GE, Gibs TD. Importance of magnesium deficiency in cardiovascular disease. American Heart Journal. 1977; $94: 649$.

[2]. Burch GE, Gibs TD. Importance of magnesium deficiency in cardiovascular disease. American Heart Journal. 1977; 94 : 649.

[3]. Whang R, Chrysant S, Dillard B et al. Hypomagnesemia and hypokalaemia in 1000 treated ambulatory hypertensive patients. J Am CollNutr. 1982; 1: 317. 
[4]. Abraham A, Shaoul R, Shimonovitz S et al. Serum magnesium levels in Acute Medical and Surgical Conditions. Biochemical Medicine. 1980; 24: 21 .

[5]. Babel S, Bhatnagar HNS, Bhatnagar BK. Serum magnesium levels in cases of acute myocardial infarction and its prognostic significance. JAPI. 1983; 31: 755-7.

[6]. Boddy K, Robertson I, Maheffy M et al. Magnesium metabolism in patients with coronary heart disease. Euro J Clin Invest 1978; 8: 87.

[7]. Turlapathy P, Althura B. Magnesium deficiency produces spasms of coronary arteries: Relationship to etiology of sudden death in IHD. Science. 1980; 208:198.

[8]. Rasmussen H, McMair P, Norregard P. et al. Effects of IV magnesium in acute myocardial infarction. Lancet. 1986 ; 1: 234.

[9]. Speich $\mathrm{M}$ et al. Concentration of magnesium, calcium, potassium and sodium in human heart muscle after acute myocardial infarction. Clin Chem. 1980; 26(12): 1662-5.

[10]. Singh RB et al. Hypomagnesemia in relation to digoxin intoxication in children. American Heart Journal. $1976 ; 92: 144$.

[11]. Dmitruk. Magnesium and calcium blood plasma content in patients with ischemic heart disease. VrachDelo. $1977 ; 2$ (14): 7.

[12]. Sachadeva et al. Serum magnesium and platelet adhesiveness in acute myocardial infarction. JIMA. 1978; $71: 165$

[13]. Ceremuzynski L, Jurgiel R et al. Threatening arrhythmias in acute myocardial infarction are prevented by intravenous magnesium sulphate. Am Heart J. 1989; 118: 1333-1334.

[14]. Shechter M, Mark N et al. Beneficial effects of magnesium sulphate in acute myocardial infarction. Am J Cardiol. 1990; 66: 271274 .

[15]. Smith LF, Heagerty AM. Intravenous infusion of magnesium sulphate after acute myocardial infarction: Effects on arrhythmias and mortality. Int J Cardiol. 1986; 12: 175-180.

[16]. Abraham AS, Rosenmann D. Magnesium in the prevention of lethal arrhythmias in acute myocardial infarction. Arch. Intern Med. 1987; 147:753-755.

[17]. Felstedt M, Boesgarurd et al. Magnesium substitution in acute ischaemic heart syndrome. Eur Heart J. 1991; 12: 1215-1218.

[18]. Singh RB, Sircar AR et al. Magnesium and potassium administration in acute myocardial infarction. Magnesium Trace Elem. 1990; 9: 198-204.

[19]. Morton BC, Nair RC et al. Magnesium therapy in acute myocardial infarction: A double blind study. Magnesium. 1984; 3: $346-352$.

[20]. Alexander RW, Gaig MP, Thomas JR et al. ST-segment elevation myocardial infarction: Clinical presentation, diagnostic evaluation and medical management. Hurst's The Heart. $11^{\text {th }}$ edition. McGraw Hill. New York. 2004: p.1277-1347. 